\title{
Interfacial Microstructure and Properties of a Vacuum Hot Roll-bonded Titanium-Stainless Steel Clad Plate with a Niobium Interlayer
}

Zongan $L U O^{1) \dagger}$, Guanglei $W A N G^{1)}$, Guangming XIE ${ }^{1)}$, Lipeng $W A N G^{2)}$ and Kun ZHAO ${ }^{1)}$

1) State Key Laboratory of Rolling and Automation, Northeastern University, Shenyang 110819, China

2) Shougang Jingtang Iron \& Steel Co., Ltd., Tangshan 063200, China

[Manuscript received 17 May 2013, in revised form 21 June 2013]

(c) The Chinese Society for Metals and Springer-Verlag Berlin Heidelberg

\begin{abstract}
Vacuum hot roll bonding (VHRB) was used to bond pure titanium (Ti) plate to a 304 stainless steel (SS) plate with a niobium $(\mathrm{Nb})$ interlayer, with the aim of producing a high-quality Ti-SS clad plate. The roll-bonding process was performed at different temperatures in the range of $850-1000{ }^{\circ} \mathrm{C}$, followed by characterization of microstructure and mechanical properties. The study demonstrates that the interfaces are free from cracks and discontinuities, and interdiffusion between the stainless steel and the titanium is effectively prevented by inserting a layer of pure $\mathrm{Nb}$ foil. No intermetallic reaction layer occurred at the Nb-Ti interface at any of the investigated temperatures. An intermetallic FeNb phase was formed at the Nb-SS interface when bonding was performed at $950{ }^{\circ} \mathrm{C}$ and above. The presence of the FeNb layer was confirmed by x-ray diffraction. The maximum shear strength of $\sim 396 \mathrm{MPa}$ was obtained when bonding is carried out at $900{ }^{\circ} \mathrm{C}$. However, the formation of the FeNb layer at roll bonding temperature greater than $900{ }^{\circ} \mathrm{C}$ led to decrease in shear strength. Ductile fracture occurred through the Ti-Nb interface for roll-bonded temperatures of up to $900{ }^{\circ} \mathrm{C}$. On the other hand, at temperature of $950{ }^{\circ} \mathrm{C}$ and above, failure occurred through the Nb-SS interface, with brittle fracture characteristics.
\end{abstract}

KEY WORDS: Vacuum hot roll bonding (VHRB); Clad plate; Interlayer; Interface; Shear strength; Intermetallic compound

\section{Introduction}

Titanium and its alloys have good erosion resistance as compared to stainless steels in majority of the corrosive environments. Thus, they are widely used in the nuclear industry for fabricating chemical equipments, heat exchangers, and offshore platforms ${ }^{[1,2]}$. However, titanium is expensive, and its plastic properties and cold forming performance is inferior compared to stainless steel. A titanium-stainless steel clad plate has both the excellent corrosion resistance of titanium and the good mechanical properties of the stainless steel, and it is cheaper because of lower

\footnotetext{
† Corresponding author. Associate Prof., Ph.D.; Tel: +86 24 83688547; Fax: +86 24 23906472; E-mail address: luoza2012@163.com (Zongan LUO)
}

DOI: $10.1007 / \mathrm{s} 40195-013-0283-9$ usage of titanium ${ }^{[3]}$. Thus, titanium-stainless steel clad plates have attracted increasing attention in recent years.

The traditional method of producing titaniumstainless steel clad plates is explosive welding. However, explosive welding has obvious disadvantages, including restriction in product size, serious environmental pollution, and lower yield ${ }^{[4-7]}$. Thus, it is being gradually replaced by vacuum hot roll bonding (VHRB). VHRB is an effective method for producing bimetallic and polymetallic plates with high bonding strength ${ }^{[8-10]}$. A vacuum electron beam welder (EBW) is used in the VHRB fabrication process to ensure vacuum between the bonding surfaces. Heating and roll-bonding processes are carried out using traditional furnace and rolling mill. The processes are simple, easy to control, and product of a wide range of sizes can be fabricated. Thus, VHRB is suitable 
Table 1 Chemical composition (wt.\%) of experimental, Ti and 304L stainless steel

\begin{tabular}{ccccccccccccc}
\hline Material & $\mathrm{C}$ & $\mathrm{N}$ & $\mathrm{H}$ & $\mathrm{O}$ & $\mathrm{P}$ & $\mathrm{S}$ & $\mathrm{Mn}$ & $\mathrm{Si}$ & $\mathrm{Cr}$ & $\mathrm{Ni}$ & $\mathrm{Fe}$ & $\mathrm{Ti}$ \\
\hline $\mathrm{Ti}$ & 0.01 & 0.02 & 0.002 & 0.14 & $/$ & $/$ & $/$ & $/$ & $/$ & $/$ & 0.07 & Bal. \\
304L SS & 0.05 & $/$ & $/$ & $/$ & 0.022 & 0.008 & 1.18 & 0.053 & 18.6 & 7.81 & Bal. & $/$ \\
\hline
\end{tabular}

for large-scale industrial production.

However, because of the limited solubility of Fe, $\mathrm{Cr}$, and $\mathrm{Ni}$ in titanium, different brittle intermetallic compounds can be nucleated at the interfaces when titanium is directly bonded to stainless steel, including the $\sigma$-phase, $\lambda$-phase, $\mathrm{TiC}, \mathrm{Fe}_{2} \mathrm{Ti}, \mathrm{FeTi}, \mathrm{Cr}_{2} \mathrm{Ti}$ and $\mathrm{NiTi}_{2}^{[11-14]}$. These intermetallic phases reduce the strength of the bond. Inserting a metal interlayer between the $\mathrm{Ti}$ and the $\mathrm{SS}$ is a potentially viable method of preventing the formation of intermetallic compounds and improving the interface bond strength. $\mathrm{Cu}, \mathrm{Ni}$, and $\mathrm{Nb}$ are generally used as interlayers. The literature suggests that intermetallic compounds of $\mathrm{Fe}$ and $\mathrm{Cu}$ or $\mathrm{Fe}$ and $\mathrm{Ni}$ are not formed. However, $\mathrm{Cu}$ and $\mathrm{Ni}$ can form intermetallic compounds with Ti, thereby severely decreasing the bond strength ${ }^{[15-18]}$. It is reported that when diffusion bonding was carried out using Ti-6Al-4V alloy and duplex stainless steel with a copper interlayer, a maximum shear strength of $107 \mathrm{MPa}$ was obtained at a bonding temperature of $900{ }^{\circ} \mathrm{C}^{[15]}$. Similarly, when diffusion bonding was carried out between pure $\mathrm{Ti}$ and $304 \mathrm{SS}$ using a Ni interlayer, a maximum shear strength of $209 \mathrm{MPa}$ was obtained at a bonding temperature of $850{ }^{\circ} \mathrm{C}^{[16]}$. Nb interlayer exhibits improved corrosion resistance and higher temperature strength than $\mathrm{Cu}$ or $\mathrm{Ni}$ interlayers ${ }^{[17]}$, and according to the Ti-Nb binary phase diagram, intermetallic compounds are not formed between $\mathrm{Ti}$ and $\mathrm{Nb}$. However, intermetallic compounds can form between $\mathrm{Fe}$ and $\mathrm{Nb}$ at high temperatures. Diffusion bonding process between pure $\mathrm{Ti}$ and $304 \mathrm{SS}$ with a Nb interlayer led to a maximum shear strength of $216 \mathrm{MPa}$ at a bonding temperature of $900{ }^{\circ} \mathrm{C}^{[19]}$. However, majority of the above studies were limited to diffusion bonding to produce joints between Ti and SS rather than clad plates. At present, there are limited studies regarding the use of VHRB to produce Ti-SS clad plates.

In the present work, Ti and SS plates were bonded by VHRB using a Nb interlayer. To obtain a highquality interface and good shear strength, the rollbonding temperature was varied from $850{ }^{\circ} \mathrm{C}$ to $1000{ }^{\circ} \mathrm{C}$. The microstructure properties and shear strengths of the obtained interfaces are presented and discussed.

\section{Experimental}

The chemical composition of the clad metal titanium plate, ASTM B265 20$]$ and the base metal 304 SS plate is presented in Table 1. $80 \mu \mathrm{m}$ thick, $99.5 \mathrm{wt} \% \mathrm{Nb}$ foil was used as the interlayer. The dimensions of Ti plates, $304 \mathrm{SS}$ plates and $\mathrm{Nb}$ foils were $120 \mathrm{~mm} \times 80 \mathrm{~mm} \times 5 \mathrm{~mm}, 120 \mathrm{~mm} \times 80 \mathrm{~mm} \times 22 \mathrm{~mm}$

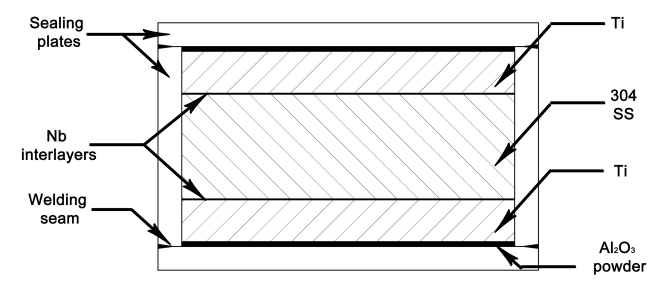

Fig. 1 Schematic diagram of the assembly form

and $120 \mathrm{~mm} \times 80 \mathrm{~mm} \times 0.08 \mathrm{~mm}$, respectively. To expose fresh metal surface, the mating surface of $\mathrm{Ti}$ plate and the SS plate were cleaned by motor wire brush, and the $\mathrm{Nb}$ foils were ground using crocus paper. The surfaces were cleaned with acetone and alcohol prior to assembly. Ti and SS cannot be welded because of the formation of brittle intermetallic compounds during the welding process ${ }^{[21]}$. Also if Ti plate is heated in an high temperature atmosphere, the surface of Ti gets terrible oxidized. So a schematic of the assembly is presented in Fig. 1. Carbon steel was used as sealing plates, which were placed as a box out to build-up slabs of Ti/SS/Ti plates. $\mathrm{Al}_{2} \mathrm{O}_{3}$ powder was placed between the sealing plate and the Ti plate to segregate the two. The build-up slabs were then put in the vacuum chamber of the EBW, and all the joints of the sealing plates were welded together to ensure vacuum in the slabs. EBW welding was performed at a welding current of $50 \mathrm{~mA}$, welding voltage of 80 $\mathrm{kV}$ and welding speed of $400 \mathrm{~mm} / \mathrm{min}$ in a vacuum of $1 \times 10^{-2} \mathrm{~Pa}$. After vacuum EBW welding, the Ti plates were taken out and wrapped with the sealing plate.

The assembled slabs were then heated in a furnace at the temperatures in the range of $850-1000{ }^{\circ} \mathrm{C}$ in steps of $50{ }^{\circ} \mathrm{C}$ for $0.5 \mathrm{~h}$. All the slabs were subjected to four rolling passes with reductions of $30 \%, 30 \%$, $40 \%$ and $40 \%$, with final total reduction of $83 \%$, followed by cooling to room temperature in air. Next, the clad plates were obtained by cutting the edges of the sealed plates and removing them.

The microstructure of the interface and the fracture caused by shear tests were observed using field emission scanning electron microscopy (SEM) (JSM$6500 \mathrm{~F}$, JEOL). The chemical composition and elemental distribution at the interface were examined using wavelength dispersive spectrometry (WDS) in a field emission electron probe microanalyser (EPMA) (JXA-8530F, JEOL). The shear tests were conducted according to the ASTM B $898^{[22]}$ standard at a strain rate of $1 \times 10^{-3} \mathrm{~s}^{-1}$. Three samples were tested for each condition. The presence of reaction products on the fracture surfaces was confirmed using an X-ray 


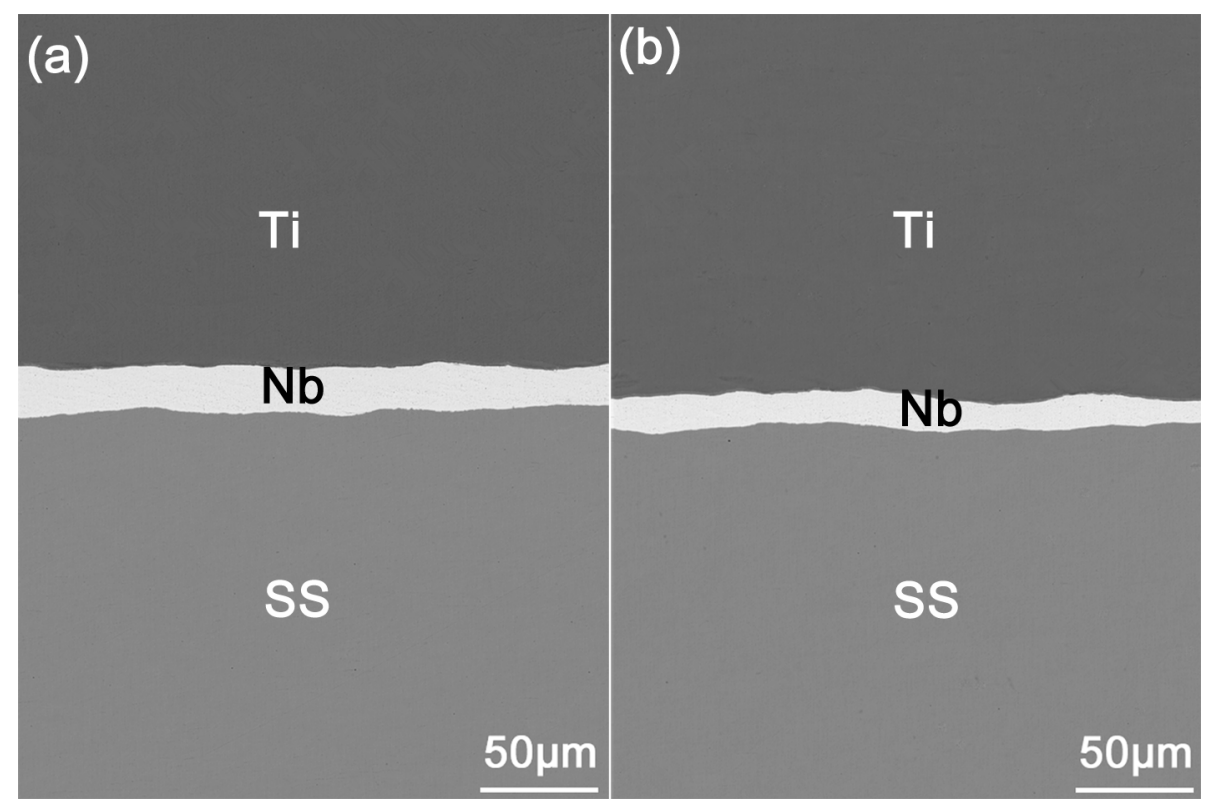

Fig. 2 Back scattered electron micrographs of the bonding interfaces roll-bonded at $900{ }^{\circ} \mathrm{C}(\mathrm{a})$ and $1000{ }^{\circ} \mathrm{C}(\mathrm{b})$

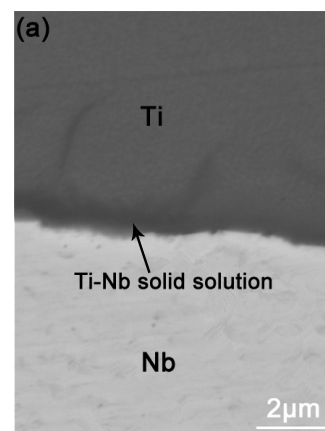

(e)

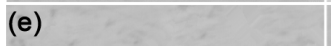

$\mathrm{Nb}$
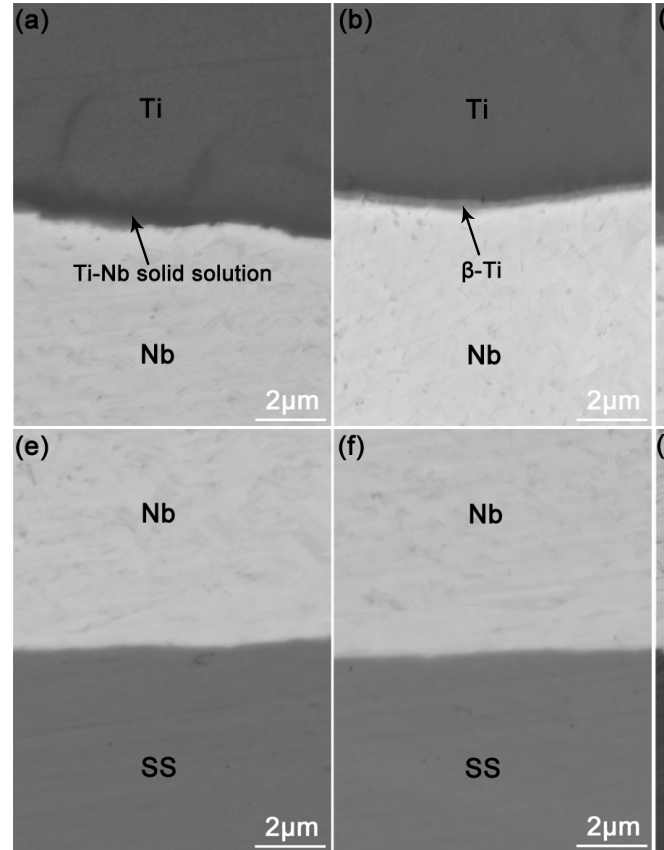

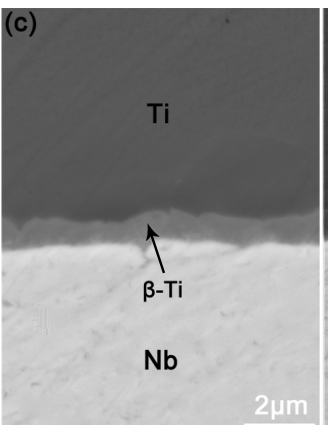

(g)

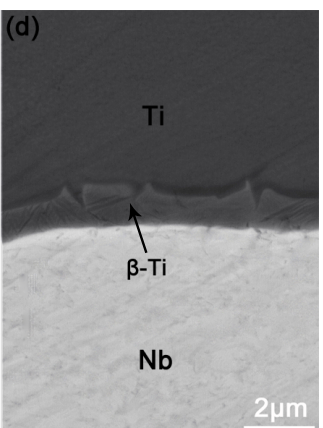

(h)
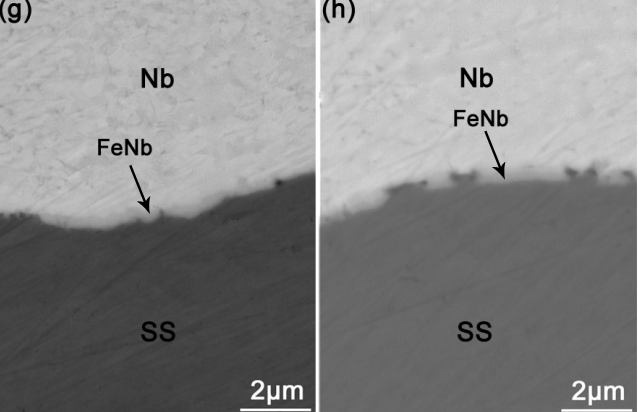

Fig. 3 Higher magnification back scattered electron micrographs images of the bonding interfaces roll bonded at different temperatures: (a, e) $850{ }^{\circ} \mathrm{C},(\mathrm{b}, \mathrm{f}) 900{ }^{\circ} \mathrm{C},(\mathrm{c}, \mathrm{g}) 950{ }^{\circ} \mathrm{C},(\mathrm{d}, \mathrm{h}) 1000{ }^{\circ} \mathrm{C}$

diffractometer (XRD) (PW3040/60, PanAnalytical). The constituents present on the fracture surfaces were examined using energy disperse spectroscopy (EDS) (INCA x-act, OXFORD).

\section{Results and Discussion}

\subsection{Microstructural characterisation of the bonding interfaces}

Fig. 2 shows the back scattered electron (BSE) micrographs of the roll bonded interfaces at $900{ }^{\circ} \mathrm{C}$ and $1000^{\circ} \mathrm{C}$. The $\mathrm{Nb}$ interlayers are bonded well with both Ti and the SS, and the bonded interfaces are free of cracks and discontinuities. Because of the large deformation generated by the roll-bonding process, the thin $\mathrm{Nb}$ interlayer became uneven and irregular at the interface. This irregular deformation of $\mathrm{Nb}$ interlayer can improve the contact between the bonded surfaces and enhance the interface bond strength by balancing the deformation on both the sides ${ }^{[8]}$.

The higher magnification BSE images of $\mathrm{Ti}-\mathrm{Nb}$ and Nb-SS interfaces are presented in Fig. 3. When rolled at $850{ }^{\circ} \mathrm{C}$, a black region consisting of $\mathrm{Ti}(96.6$ 97.4 wt.\%) and $\mathrm{Nb}(2.6-3.4$ wt.\%) is present on the Ti 

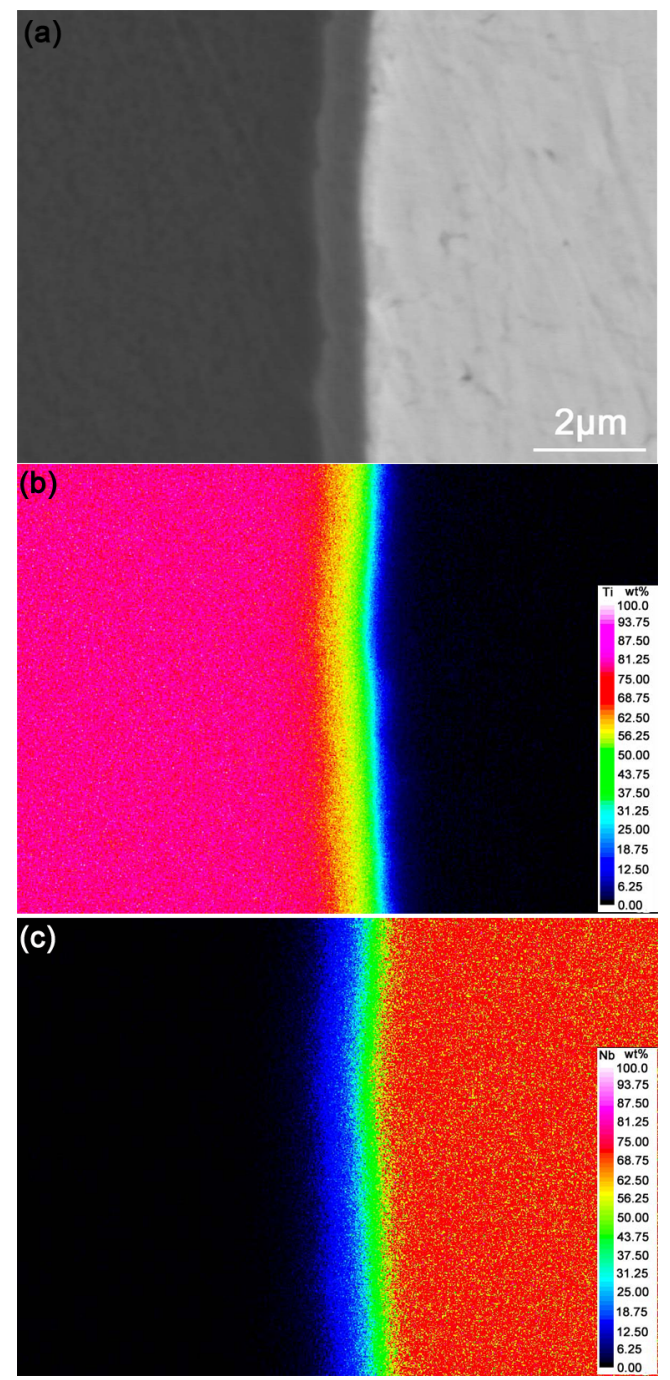

Fig. 4 Elemental distributions along the Ti-Nb interface roll-bonded at $950^{\circ} \mathrm{C}$ : (a) BSE image, (b) Ti map, (c) $\mathrm{Nb}$ map

side adjacent to the Ti-Nb interface. According to the $\mathrm{Ti}-\mathrm{Nb}$ binary phase diagram, this region is $\alpha$-Ti solid solution with a small amount of $\mathrm{Nb}$ due to diffusion of $\mathrm{Nb}$ into $\alpha-\mathrm{Ti}^{[23]}$. When the roll bonding temperature was increased to $900{ }^{\circ} \mathrm{C}$ and above, reaction layer appeared on the Ti side in the vicinity of the $\mathrm{Ti}-\mathrm{Nb}$ interface. Fig. 4 presents the elemental distribution of the $\mathrm{Ti}-\mathrm{Nb}$ interface rolled at $950^{\circ} \mathrm{C}$. The diffusion concentration gradient of $\mathrm{Nb}$ and $\mathrm{Ti}$ in this reaction layer is clearly visible. The WDS analysis suggested that this layer is enriched with $\mathrm{Ti}$ (55.4 wt.\%-71.7 wt.\%) and $\mathrm{Nb}(28.3$ wt.\%-43.6 wt.\%). Based on the binary phase diagram of $\mathrm{Ti}-\mathrm{Nb}$, this is $\beta-\mathrm{Ti}^{[23]}$. For pure titanium, complete $\alpha-\beta$ phase transformation temperature occurs at $882{ }^{\circ} \mathrm{C}$, but when the temperature is greater than this phase transformation point, $\alpha$-Ti transforms to $\beta$-Ti. $\mathrm{Nb}$ is a strong $\beta$-stabilising element and migration of $\mathrm{Nb}$ atoms into the Ti lattice lowers the eutectoid transformation temperature of titanium. On cooling after the roll-bonding process, majority of the $\beta$-Ti in the bulk Ti is transformed back to $\alpha$-Ti, but
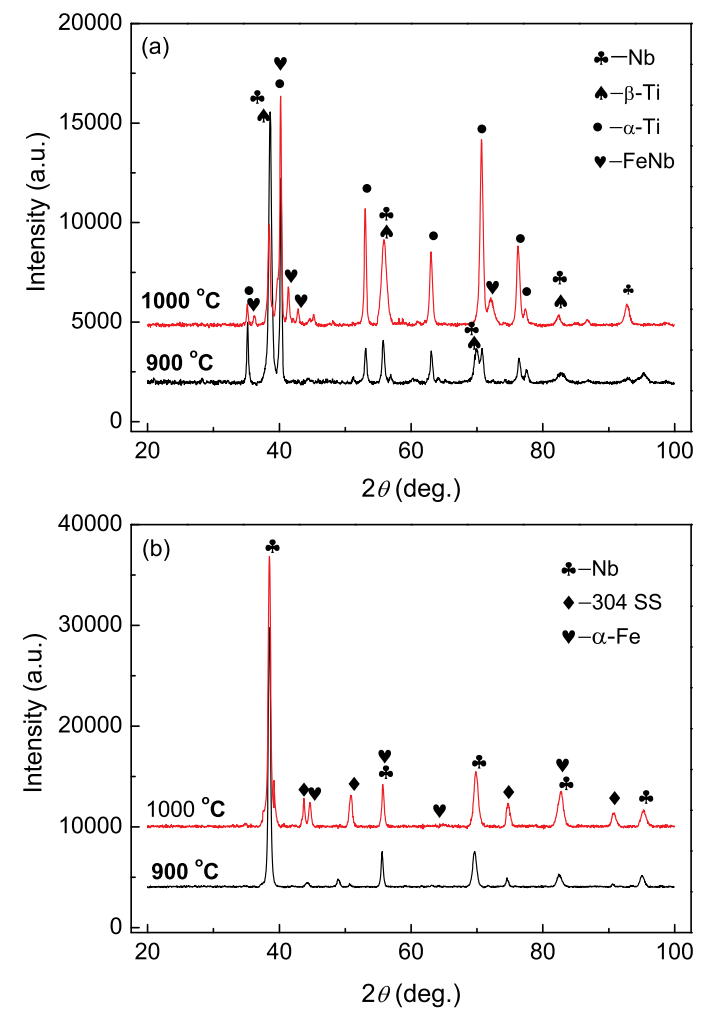

Fig. 5 X-ray diffraction patters obtained from the titanium (a) and stainless steel (b) sides

some $\beta$-Ti near the Ti-Nb interface remains in the $\beta$ $\mathrm{Ti}$ phase at room temperature due to enrichment by $\mathrm{Nb}$. When the roll bonded temperature is $900{ }^{\circ} \mathrm{C}$, $950{ }^{\circ} \mathrm{C}$ and $1000{ }^{\circ} \mathrm{C}$, the average thicknesses of the $\beta$ Ti layers were $0.26 \mu \mathrm{m}, 0.79 \mu \mathrm{m}$ and $1.30 \mu \mathrm{m}$, respectively, and the relationship of the thicknesses of the layers was linear with the roll bonding temperature. Due to diffusion is limited at lower temperatures, $\beta$ $\mathrm{Ti}$ does not exist at room temperature at the $\mathrm{Ti}-\mathrm{Nb}$ interface, roll bonded at $850{ }^{\circ} \mathrm{C}$. The above analysis demonstrates that the $\mathrm{Ti}-\mathrm{Nb}$ interfaces are free from intermetallic compounds.

At the $\mathrm{Nb}-\mathrm{SS}$ interface, no obvious reaction or diffusion layer is observed at roll bonded temperatures of $850{ }^{\circ} \mathrm{C}$ and $900{ }^{\circ} \mathrm{C}$. However, when the roll bonded temperature increases to $950{ }^{\circ} \mathrm{C}$ or above, a thin a diffusion layer was observed on the $\mathrm{Nb}$ side near the interface. WDS analysis revealed that this thin layer consisted of $\mathrm{Nb}(66.2$ wt.\%-68.9 wt.\%), Fe (24.7 wt.\%-27.5 wt.\%), Cr (3.1 wt.\%-5.4 wt.\%) and $\mathrm{Ni}$ (bal.). According to the Fe-Nb binary phase diagram, this layer is most likely to be a FeNb intermetallic compound ${ }^{[23]}$. As presented in Fig. 5, the results of the XRD analysis on both sides of the shear-fractured surfaces of sample bonded at $1000{ }^{\circ} \mathrm{C}$, where fracture occured through the $\mathrm{Nb}-\mathrm{SS}$ interface (see section 3.3), confirmed the presence of FeNb phase on the Ti side. $\mathrm{FeNb}$ is a brittle intermetallic phase and was discontinuously distributed along the interfaces (Fig. 3(g) and Fig. 3(h)). In this experiment, as roll-bonding process is carried at high temperature for a short time, 

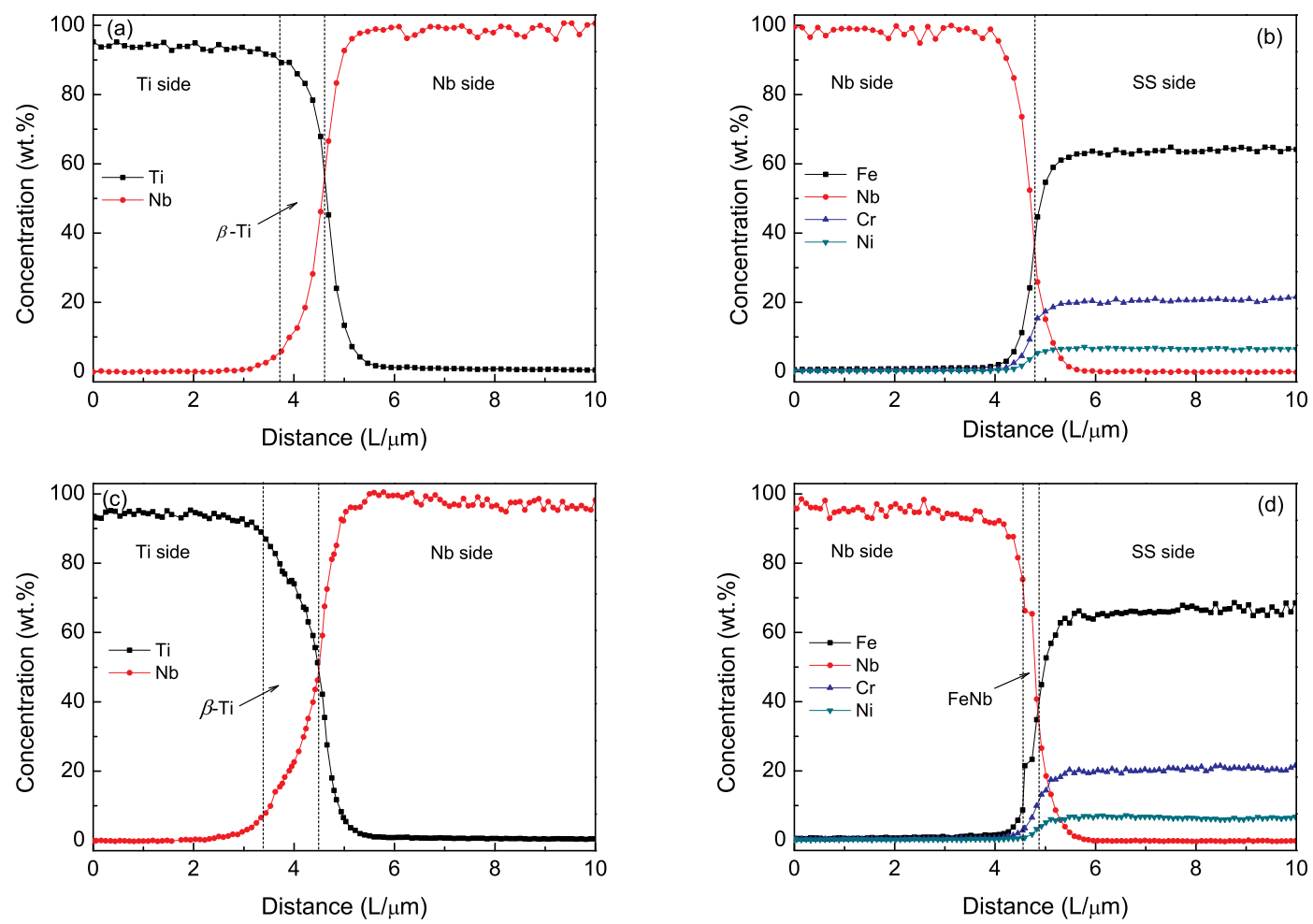

Fig. 6 Concentration profiles of the bonding interfaces rolled at $900{ }^{\circ} \mathrm{C}$ and $1000{ }^{\circ} \mathrm{C}$ : (a) $900{ }^{\circ} \mathrm{C}$, Ti-Nb interface; (b) $900{ }^{\circ} \mathrm{C}$, Nb-SS interface; (c) $1000{ }^{\circ} \mathrm{C}$, Ti-Nb interface; (d) $1000{ }^{\circ} \mathrm{C}$, Nb-SS interface

there is not enough time for the continuous layer to form. Thus, a discontinuous intemetallic island as compared to a complete layer appears at the Nb-SS interface.

Fig. 6 presents the elemental concentration of the $\mathrm{Ti}-\mathrm{Nb}$ and Nb-SS interfaces. Elemental interdiffusion is observed at both Ti-Nb and Nb-SS interfaces, while no interdiffusion is observed between the Ti and SS. Hence, the $\mathrm{Nb}$ interlayer effectively prevents diffusion between Ti and SS. As the temperature increases, the level of interdiffusion also increases. Fig. 6(a) and Fig. 6(c) demonstrate that more $\mathrm{Nb}$ atoms migrate to the Ti side at the roll bonded temperature of $1000{ }^{\circ} \mathrm{C}$ than at $900{ }^{\circ} \mathrm{C}$, and the $\beta$-Ti region shown in the $1000{ }^{\circ} \mathrm{C}$ plot is wider than that in the $900{ }^{\circ} \mathrm{C}$ plot. Increased diffusion at higher temperatures also leads to the formation of FeNb. In Fig. 6(b), the diffusion plot at the Nb-SS interface is smooth because there is no intermetallic layer. However, in Fig. 6(d), a small concentration inflection is visible at the $\mathrm{Nb}$ side near the Nb-SS interface, representing the FeNb region. The SS has an fcc crystal structure, and $\mathrm{Nb}$ has a bcc crystal structure with more open space. Due to the more open crystallography of the bcc lattice, Fe atoms can travel a longer distance into the $\mathrm{Nb}$ lattice than the $\mathrm{Nb}$ atoms can travel into the SS. Therefore, $\mathrm{FeNb}$ forms on the $\mathrm{Nb}$ side rather than on the SS side.

\subsection{Mechanical properties of the bonded interfaces}

The shear strengths of the bonded interfaces are presented in Fig. 7 as a function of the roll bonding

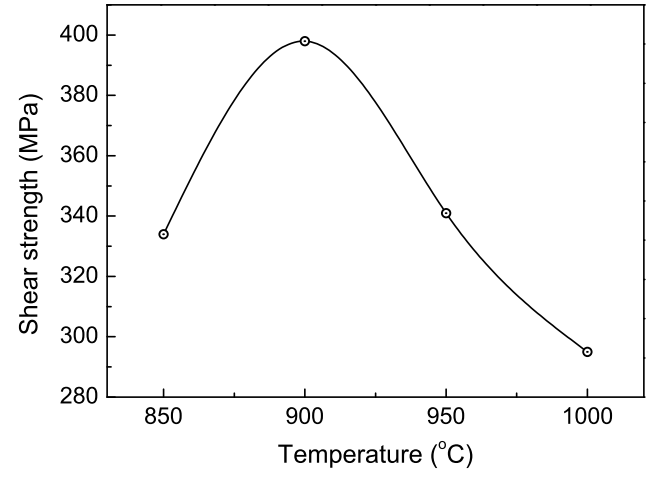

Fig. 7 Interface shear strengths of the clad plates rollbonded at different temperatures

temperature. The maximum average shear strength value of $\sim 396 \mathrm{MPa}$ was achieved in the samples roll bonded at $900{ }^{\circ} \mathrm{C}$. At roll bonding temperature of $850{ }^{\circ} \mathrm{C}$, lower average shear strength of $\sim 335 \mathrm{MPa}$ was obtained because the yield stress of the material remains high and diffusion is limited at the interface. Diffusion is promoted with increase in roll bonding temperature, which strengthens the $\mathrm{Ti}-\mathrm{Nb}$ interface, but also contributes to the formation of FeNb at the Nb-SS interface. When the rolling temperature was $950{ }^{\circ} \mathrm{C}$ or higher, FeNb intermetallic compound formed at the $\mathrm{Nb}-\mathrm{SS}$ interface, and its volume fraction increased with increase in roll bonding temperature. Thus, the shear strength gradually decreases, and the lowest value of $\sim 296 \mathrm{MPa}$ was obtained at $1000{ }^{\circ} \mathrm{C}$. The ASTM B898 standard ${ }^{[22]}$ requires minimum 
shear strength of Ti-SS clad plate to be $140 \mathrm{MPa}$. The shear strengths of all of these Ti-SS clad plates exceeded the minimum standard.

In a prior study, when the diffusion-bonding (DB) process was carried out between pure $\mathrm{Ti}$ and $304 \mathrm{SS}$ using a $\mathrm{Nb}$ interlayer with the same heating process parameters as the present study, the maximum shear strength obtained was $\sim 216 \mathrm{MPa}$ at bonding temperature of $900{ }^{\circ} \mathrm{C}^{[19]}$. The bonding strength of the same interface produced by VHRB is significantly high. During the DB process, the surface is subjected to only a small vertical load, and there is no or little deformation along the diffusion interface. In contrast, the VHRB process subjects the surface to both a higher roll bonding pressure and a higher frictional shear force, and the slabs consequently experience a significant degree of deformation. Thus, the oxidation film on the surface is easily ruptured, and fresh metal is exposed, which enables good bonding. In addition, the roll-bonding time of VHRB is significantly smaller than in DB. The intimate contact of surfaces at a high temperature for a short time results in significantly reduced volume fraction of intermetallic compounds at the roll-bonding interface ${ }^{[8]}$. All of the above conditions contribute to the improved shear strength of the VHRB interfaces.

\subsection{Fracture surface of the bonded interfaces}

SEM micrographs of the fracture surfaces are present in Fig. 8. Only a small amount of $\mathrm{Nb}$ foil is left at the $\mathrm{Ti}$ side of the shear sample rolled at
$900{ }^{\circ} \mathrm{C}$ (Fig. 8(a)), indicating that majority of the fracture occurred through the $\mathrm{Ti}-\mathrm{Nb}$ interface rather than through the Nb-SS interface, which means that the bond strength of the $\mathrm{Ti}-\mathrm{Nb}$ interface is lower than that of the Nb-SS interface. In contrast, at higher rolling temperature of $1000{ }^{\circ} \mathrm{C}$, fracture occurred through the $\mathrm{Nb}-\mathrm{SS}$ interface, and more of the $\mathrm{Nb}$ foil was left on the Ti side (Fig. 8(b)). And because $\mathrm{FeNb}$ formed on the $\mathrm{Nb}$ side rather than on the SS side as analyzed in section 3.1, FeNb was left on the Ti side with $\mathrm{Nb}$ interlayer after shear rupture. Therefore, FeNb phase was only detected in the $\mathrm{Ti}$ side as shown in Fig. 5.

High magnification micrographs of the shear fracture at $\mathrm{Ti}-\mathrm{Nb}$ interface of the samples roll bonded at $900{ }^{\circ} \mathrm{C}$ and $1000{ }^{\circ} \mathrm{C}$ are presented in Fig. 8(c) and Fig. 8(d), respectively. As can be seen from the fractographs, the mode of fracture was dimple rupture on the interface of $\mathrm{Ti}-\mathrm{Nb}$ at these two temperatures. Fig. 9(a) shows the EDAX results of points 1 and 2 in Fig. 8, and the results in Table 2 show that $\mathrm{Nb}$ is associated with the vast majority of the fracture surface, suggesting that the fracture location lies at the interface towards $\mathrm{Nb}$ layer side. The above results imply formation of a good $\mathrm{Ti}-\mathrm{Nb}$ interface.

Fig. 8(e) and Fig. 8(f) are high magnification micrographs of the bonding samples shear fracture at the interface of Nb-SS. Nb-SS fracture shows river pattern, indicating a brittle mode of fracture. There are also many micro-cracks within the river pattern at $1000{ }^{\circ} \mathrm{C}$. Fig. 9(b) shows the EDAX analysis of the Nb-SS fracture. The data in Table 2 suggest that

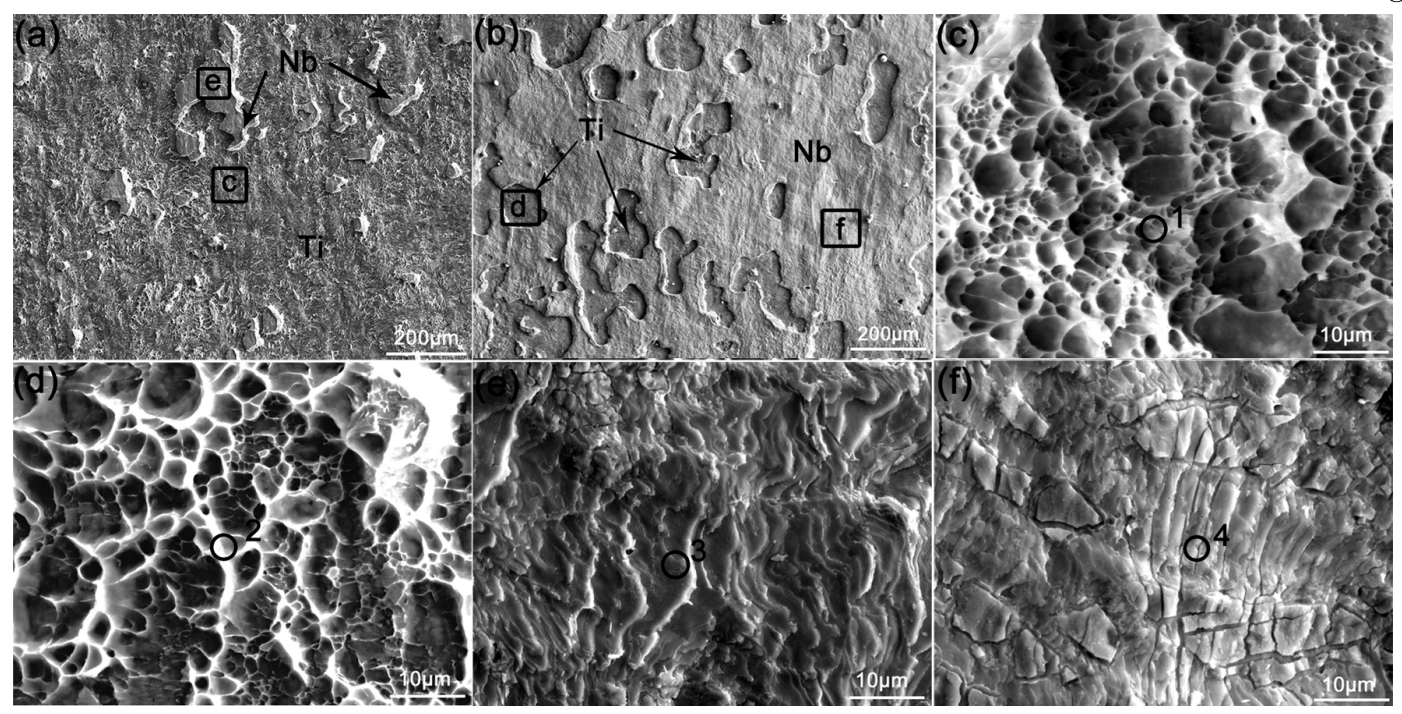

Fig. 8 Fracture surfaces on the Ti side of the bonded samples: (a, c, e) $900{ }^{\circ} \mathrm{C}$; (b, d, f) $1000{ }^{\circ} \mathrm{C}$

Table 2 EDAX analysis data of the points shown in Fig. 8

\begin{tabular}{ccccccccc}
\hline Element & \multicolumn{8}{c}{ Content } \\
\cline { 2 - 9 } & \multicolumn{2}{c}{ Point 1 } & \multicolumn{1}{c}{ Point 2 } & Point 3 & \multicolumn{2}{c}{ Point 4 } \\
\cline { 2 - 9 } & wt.\% & at.\% & wt.\% & at.\% & wt.\% & at.\% & wt.\% & at.\% \\
\hline $\mathrm{Ti}$ & 10.32 & 18.24 & 20.13 & 32.83 & - & - & - & - \\
$\mathrm{Nb}$ & 89.68 & 81.76 & 79.87 & 97.17 & 98.19 & 96.87 & 95.11 & 92.05 \\
$\mathrm{Fe}$ & - & - & - & - & 1.36 & 2.24 & 3.72 & 5.99 \\
$\mathrm{Cr}$ & - & - & - & - & 0.45 & 0.79 & 0.83 & 1.44 \\
$\mathrm{Ni}$ & - & - & - & - & - & - & 0.34 & 0.52 \\
\hline
\end{tabular}



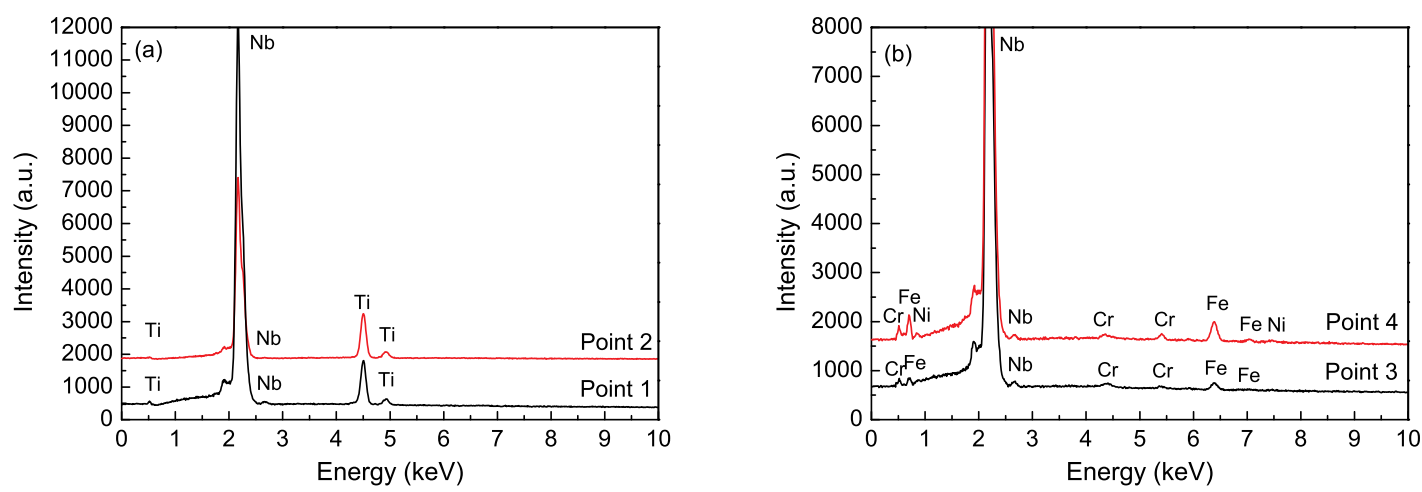

Fig. 9 EDAX analyses of the points on the fracture surfaces shown in Fig. 8: (a) Point 1 and Point 2, (b) Point 3 and Point 4

$\mathrm{Nb}$ layer on the fracture contains $\mathrm{Fe}, \mathrm{Cr}$, and $\mathrm{Ni}$ that has diffused from the SS side to the $\mathrm{Nb}$ side, especially the bulk diffusion of $\mathrm{Fe}$, leading to the formation intermetallic compound, and making the Nb layer brittle. With increase in temperature, greater diffusion of $\mathrm{Fe}$ and $\mathrm{Cr}$ took place such that the thicker intermetallic compound promoted brittle behavior. Thus, Nb-SS interface exhibited characteristics of brittle fracture, at the high temperature of $1000{ }^{\circ} \mathrm{C}$.

\section{Conclusions}

(1) Ti-SS clad plate bonded by VHRB using $\mathrm{Nb}$ interlayer exhibited excellent properties. The bonded interfaces were free of cracks and discontinuities and the shear strength of the interface was significantly higher than the minimum standard.

(2) The Ti-Nb interface was free from intermetallic compounds at all the investigated roll bonding temperatures. The Nb-SS interfaces were free from reaction products for roll bonding temperatures up to $900{ }^{\circ} \mathrm{C}$. However, at temperatures greater than $950{ }^{\circ} \mathrm{C}$ and above, FeNb intermetallic compound formed at the interface. Increasing the roll bonding temperature promotes elemental diffusion and consequently the formation of FeNb.

(3) The maximum interface shear strength of $\sim 396$ $\mathrm{MPa}$ was obtained at roll bonding temperature of $900{ }^{\circ} \mathrm{C}$, and ductile fracture occurred through the Ti$\mathrm{Nb}$ interface. At higher roll bonding temperatures exceeding $900{ }^{\circ} \mathrm{C}$, there was decrease in shear strength, and brittle cleavage type fracture occured through the $\mathrm{Nb}-\mathrm{SS}$ interface because of the formation of brittle FeNb intermetallic compound.

\section{Acknowledgement}

This work was financially supported by the Fundamental Research Funds for Chinese Central Universities (No. N110607001) and National High Technical Research and Development Programme of China (No. 2013AA031302).

\section{REFERENCES}

[1] G. Lutjering and J.C. Williams, Titanium, Springer,
Berlin, 2007, pp.5-18.

[2] M. Ghosh and S. Chatterjee, Mater. Charact. 54 (2005) 327.

[3] K. Fumio, Surf. Interface. Anal. 12 (1988) 203.

[4] P. Manikandan, K. Hokamoto, M. Fujita, K. Raghukandan and R. Tomoshigee, J. Mater. Process Technol. 195 (2008) 232.

[5] S.A.A. Akbari Mousavi and P. Farhadi Sartangi, Mater. Des. 30 (2009) 459.

[6] J. Song, A. Kostka, M. Veehmayer and D. Raabe, Mater. Sci. Eng. A 528 (2011) 2641.

[7] F. Fehim. Mater. Design. 32 (2011) 1081.

[8] D.S. Zhao, J.C. Yan, Y. Wang and S.Q. Yang, Mater. Sci. Eng. A 499 (2009) 282.

[9] G.M. Xie, Z.A. Luo, G.L. Wang, L. Li and G.D. Wang, Mater. Trans. 52 (2011) 1709.

[10] Y.M. Hwang, H.H. Hsu and Y.L. Hwang, Int. J. Mech. Sci. 42 (2000) 2417.

[11] G.B. Kale, R.V. Patil and P.S. Gawade, J. Nucl. Mater. 257 (1998) 44.

[12] B. Qin, G.M. Sheng, J.W. Huang, B. Zhou, S.Y. Qiu and C. Li, Mater. Charact. 56 (2006) 32.

[13] M. Ghosh, K. Bhanumurthy, G.B. Kale, J. Krishnan and S. Chatterjee, J. Nucl. Mater. 322 (2003) 235.

[14] T. Vigraman, D. Ravindran and R. Narayanasamy, Mater. Des. 36 (2012) 714.

[15] M. Eroglu, T.I. Khan, N. Orhan, Mater. Sci. Technol. 18 (2002) 68.

[16] S. Kundu and S. Chatterjeem, J. Mater. Sci. 42 (2007) 7906.

[17] J.C. Yan, D.S. Zhao, C.W. Wang, L.Y. Wang, Y. Wang and S.Q. Yang, Mater. Sci. Technol. 25 (2009) 914.

[18] A. Elrefaey and W. Tillmann, J. Mater. Process. Technol. 209 (2009) 2746.

[19] S. Kundu and S. Chatterjee, ISIJ. Int. 50 (2010) 1460.

[20] ASTM B265-11. Standard Specification for Titanium and Titanium Alloy Strip, Sheet, and Plate. ASTM International, 1 September, 2011.

[21] S.A.A. Akbarimousavi and M. GohariKia, Mater. Design. 32 (2011) 3066.

[22] ASTM B898-11. Standard Specification for Reactive and Refractory Metal Clad Plate. ASTM International, 1 September, 2011.

[23] H. Baker, ASM Handbook: Alloy Phase Diagrams. ASM International, Ohio, 1992, pp.158-205. 